\title{
The Clinical Complexity of Penile Cancer: Current Clinical-Epidemiological Data from the Database of the Free State of Saxony/Germany
}

\author{
Wolf-Diether U. Boehm ${ }^{\mathrm{a}}$ Daniela Piontek ${ }^{\mathrm{b}}$ Stefanie Latarius ${ }^{\mathrm{c}}$ Olaf Schoffer ${ }^{\mathrm{d}}$ \\ Angelika Borkowetz ${ }^{c}$ Stefanie J. Klug ${ }^{\mathrm{e}}$ Manfred P. Wirth ${ }^{\mathrm{C}}$ \\ ${ }^{a}$ Academic Student Training Consultation for Urology, Technical University Dresden, Dresden, Germany; ${ }^{\text {b Joint }}$ \\ Office of the Clinical Cancer Registries in Saxony, The State Chamber of Physicians of Saxony, Dresden, Germany; \\ 'Department of Urology, University Hospital, Technical University Dresden, Dresden, Germany; ${ }^{\mathrm{d} C e n t r e}$ of

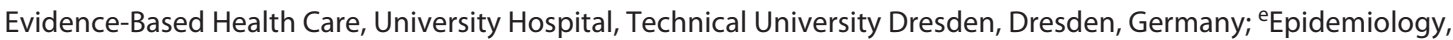 \\ Department of Sport and Health Sciences, Technical University Munich, Munich, Germany
}

\section{Keywords}

Penile cancer · Clinical cancer registry · Quality indicators · Survival

\begin{abstract}
Objectives: The aim of this study was to assess penile cancer incidence, clinical characteristics, treatment options, transparency of clinical quality, and relative survival based on data from the clinical cancer registry. Subjects and Methods: A total of 898 patients with tumours of the penis were diagnosed and analysed in the period from 2000 to 2018; they were documented in the 4 regional clinical cancer registries and summarized in the Command Office of these 4 registries. Results: The standardized incidence rate increased from 0.86 in 2000 to 2.67 in 2018. Most tumours were located at the glans (42.9\%) followed by the prepuce (19.5\%) and corpus penis (6.9\%); they were classified into pT1a/pT1b (20.0\%/7.0\%), pT2 (23.5\%), pT3 (12.4\%), and pT4 (0.8\%). In
\end{abstract}

karger@karger.com www.karger.com/uin

Karger $\stackrel{\text { ' }}{5}$

GOPEN ACCESS
(C) 2021 The Author(s)

Published by S. Karger AG, Basel

This is an Open Access article licensed under the Creative Commons Attribution-NonCommercial-4.0 International License (CC BY-NC) (http://www.karger.com/Services/OpenAccessLicense), applicable to the online version of the article only. Usage and distribution for commercial purposes requires written permission. only $32.0 \%$ of all documented cases, a stage-related lymphadenectomy (LND) was carried out. Negative surgical margins were found in only $70 \%$ and the Rx status in $15.1 \%$. Primary metastasis was detected in pN1 (5.1\%), pN2 (3.9\%), pN3 (3.1\%), and $\mathrm{M} 1$ status in $3.0 \%$, respectively. The predominant therapy was surgery in $78.3 \%$. The proportion of penile partial resections was significantly $(p=0.0045)$ regredient over the control period. Adjuvant chemotherapy was performed in $4.7 \%$, adjuvant external-beam radiotherapy in $3.0 \%$. The 5 -year relative overall survival rate was $74.7 \%$ and ranged from $108.0 \%$ (stage 0 ) to $17.1 \%$ (stage IV). A total of 29 hospitals performed tumour operations. Conclusions: The multitude of clinical and epidemiological variables available in clinical cancer registries allows a safe assessment of tumour dynamics themselves, as well as good quality of transparency and broadly acceptable guideline adherence. Deviations from the accepted level of evidence were found in the grading definition, in the high quota of positive surgical margins, in the defensive indication position to the glans resur- 
facing/reconstruction and diagnostical LND. Based on these relevant findings in the database combined with the low frequency of the tumour in area/clinics/year, we recommended establishing SCCP reference clinics. This work is the first time that European standardized rate-based cancer registry data on penile cancer from Germany has been communicated.

(C) 2021 The Author(s)

Published by S. Karger AG, Basel

\section{Introduction}

Penile cancer continues to be regarded as an absolute rare tumour entity in Europe. The incidence rate varies currently between 0.59 per 100,000 (European standardized rate [ESR]) in France, 0.91 per 100,000 in Norway, and 2.1 per 100,000 in Sweden [1-3]. A relatively low incidence rate of 0.58 per 100,000 (US standard population) across all ethnic groups was reported for the USA [4]. Higher incidence rates continue to be documented in South America, Asia, and sub-Saharan Africa $[5,6]$. In 2019, Schoffer et al. reported an epidemiological analysis of Saxony using the data of the Common Cancer Registry of Berlin for the period from 1961 to 2012. The age-standardized incidence rate was undulating from 0.7 (ESR) in 1968 and increased to 1.8 (ESR) by the year of 2012. The relative 5-year survival rate (overall survival) was estimated to be $72.4 \%$, while mortality decreased to 0.3 per 100,000 in 2012 [6].

The low incidence level as well as the relative good 5 -year survival rate in the local stage was over $70 \%[2,3$, 7], veiled the fact that there are highly intrinsic risks (local clinical staging, grading discussion, and low chemosensitivity) involved with this tumour. Thus, many hospitals rarely encounter multiform penile cancer; in 2018, one pathologist evaluated statistically a primary SCCP in Germany only once every 17 months - with implications for optimal individual clinical-oncological management [8].

In this context, the situation is exacerbated by the fact that this carcinoma hardly responds to systemic therapy in palliative situation for advanced/metastasised stage with a response rate of 30-38\% - and therefore only over a short time [7]. Moreover, both the indication of radiation therapy as well as external-beam radiation therapy (EBRT) and brachytherapy continue to be regarded sceptically in Europe [7]; by contrast, they are practised more offensively in the USA and the United Kingdom [9-11]. The aim of this work was to evaluate the externally defined data quality of the registry data for their clinicalscientific applicability.

Current Clinical-Epidemiological Data

\section{Subjects and Methods}

Design

Practitioners and hospitals deliver information based on the standard oncological dataset of the ADT - Working group of German Tumour Centres and the GEKID - Society of Populationbased Cancer Registries in Germany [12]. Completeness of the registries has been estimated 98\% over all tumours since 2007 [13]. For the present analyses, all registered cases with ICD-10 diagnoses $\mathrm{C} 60^{*}$ and D07.4 were considered that they were diagnosed in the period from 2000 to 2018 . Registry data were extracted on thirtieth November 2019. Within the period from 2000 to 2018, a total of 952 tumours of the penis were documented in the 4 clinical cancer registries. We excluded 54 cases with documented melanoma, Morbus Bowen, and Erythroplasia de Queyrat. The analytical sample thus comprised 898 cases.

\section{Included Variables}

Tumour localization was documented according to the International Classification of Diseases for Oncology. The TNM classification was used for describing the extent of spread of cancer, including the resulting stages according to the Union for International Cancer Control (UICC) (stages 0, I, II, III, IV, and missing) and histopathological grade (G1, G2, G3/G4, and missing) [14]. The post-surgical histopathological classification of the TNM (pTNM) was used. Regarding penile cancer, a relevant modification was introduced in the seventh edition of TNM published in 2010 splitting the T1 category into T1a and T1b. When distant metastases were present, their location was considered if the metastasis was documented within 3 months (92 days) after diagnosis.

Surgeries were documented according to the German procedure classification [15]. Only tumour-specific resections and excisions were considered (circumcision, local excision including laser therapy, partial amputation, and total amputation). Lymph node dissections were analysed separately; residual tumour classification (R classification) was assessed (R0, R1, R2, and RX/missing). Cancer recurrences were documented according to where they occurred (primary tumour, lymph nodes, and distant metastases) in the follow-up.

In total, 29 clinical departments were registered. In Germany, federal and regional statutory rules define the process of data collection and storage in clinical cancer registries. All inpatient and outpatient physicians as well as pathologists are obliged to report information on diagnosis, histological results, treatment, and outcomes to the clinical cancer registries. Patients need to be informed about this process. However, they do not need to consent. Patients have a right of objection which is hardly used (fewer than 5 cases/ year in Saxony). After documentation and validation of the data, data analysis is done with an anonymized dataset that does not allow identification of individual patients.

\section{Statistical Analyses}

For descriptive purposes, absolute numbers and percentages are presented. Standardized incidence rates per 100,000 inhabitants were calculated using the ESR. The annual percentage change and the respective $95 \%$ confidence intervals (CIs) were estimated to investigate changes in trends for the respective time periods. Trend changes were investigated over time. The trend analysis for the percentage of partial resections is based on simple linear regression.

Five-year relative survival rates with corresponding 95\% CIs were calculated based on the Kaplan-Meier estimation using the 
Table 1. Clinical characteristics of the tumours diagnosed in the period 2000-2018

\begin{tabular}{|c|c|c|}
\hline & $N$ & $\%$ \\
\hline Total number of tumours & 898 & 100.0 \\
\hline D07.4 & 69 & 7.7 \\
\hline \multicolumn{3}{|l|}{ Localization } \\
\hline C60.0 prepuce & 179 & 19.9 \\
\hline C60.1 glans penis & 445 & 49.6 \\
\hline C60.2 body of penis & 62 & 6.9 \\
\hline C60.8 overlapping lesions of penis & 107 & 11.9 \\
\hline C60.9 penis, unspecified & 105 & 11.7 \\
\hline \multicolumn{3}{|l|}{ Histopathological grade } \\
\hline G1 & 233 & 25.9 \\
\hline $\mathrm{G} 2$ & 385 & 42.9 \\
\hline G3/G4 & 177 & 19.7 \\
\hline GX/missing & 103 & 11.5 \\
\hline \multicolumn{3}{|l|}{ pT stage } \\
\hline $\mathrm{pTa}$ & 11 & 1.2 \\
\hline pTis & 56 & 6.2 \\
\hline pT1 & 174 & 19.4 \\
\hline pT1a & 180 & 20.0 \\
\hline pT1b & 63 & 7.0 \\
\hline pT2 & 211 & 23.5 \\
\hline pT3 & 111 & 12.4 \\
\hline pT4 & 7 & 0.8 \\
\hline $\mathrm{pTX} /$ missing & 85 & 9.5 \\
\hline \multicolumn{3}{|l|}{ pN stage } \\
\hline pNO & 135 & 15.0 \\
\hline pN1 & 46 & 5.1 \\
\hline $\mathrm{pN} 2$ & 35 & 3.9 \\
\hline pN3 & 28 & 3.1 \\
\hline No Lymph node dissection/pNX & 654 & 72.8 \\
\hline \multicolumn{3}{|l|}{ pM stage } \\
\hline pMO & 871 & 97.0 \\
\hline pM1 & 27 & 3.0 \\
\hline \multicolumn{3}{|l|}{ pUICC stage } \\
\hline 0 & 64 & 7.1 \\
\hline I & 317 & 35.3 \\
\hline II & 253 & 28.2 \\
\hline III & 90 & 10.0 \\
\hline IV & 60 & 6.7 \\
\hline Missing & 114 & 12.7 \\
\hline
\end{tabular}

Ederer II method and cohort approach. Relative survival rates represent survival of the patients in comparison to the general population of the same age and sex. Data on general population mortality were retrieved from the Statistical Office of Saxony. Survival analyses included only primary tumours and cases with a minimum survival time of one month $(n=749)$. Descriptive and survival analyses were conducted using the programme R 3.6.0. Trend analyses were performed with the Joinpoint Regression Program (Version 4.2.0.2, Statistical Research and Applications Branch, NCI, Bethesda, MD).
Table 2. Primary tumour and lymph node surgery, residual tumour classification, and cancer recurrence of the tumours diagnosed in the period 2000-2018

\begin{tabular}{lll}
\hline & $N$ & $\%$ \\
\hline Tumour-specific surgery & & \\
$\quad$ Circumcision & 102 & 13.0 \\
$\quad$ Local excision including laser therapy & 135 & 17.2 \\
$\quad$ Partial amputation & 459 & 58.4 \\
$\quad$ Total amputation & 90 & 11.5 \\
Total & 786 & 100.0 \\
$\quad$ Lymph node dissection & 287 & 32.0 \\
Residual tumour classification & & \\
R0 & 556 & 70.7 \\
R1 & 51 & 6.5 \\
R2 & 60 & 7.6 \\
RX/missing & 119 & 15.1 \\
Cancer recurrence & & \\
Local recurrence & 78 & 8.7 \\
Lymph nodes & 66 & 7.3 \\
Distant metastases & 25 & 2.8 \\
\hline
\end{tabular}

\section{Results}

Tables 1 and 2 show all clinical characteristics of tumours diagnosed in the period from 2000 to 2018. In about half of all the cases (49.6\%), the tumour was localized on the glans, followed by the prepuce with $19.9 \%$. Most of the tumours were included in the categories pT2 $(23.5 \%)$ or pT1a (20.0\%) (online suppl. Fig. 3; for all online suppl. material, see www.karger.com/doi/10.1159/000519210). The prognostically significant differentiation in the T1a/T1b category was widely introduced on a regular basis in pathological institutes in 2010. This results in the apparent proportional changes for the pT1 also during the documentation in $8.3 \%$ of the cases; however, the "pT1" continues to be conventionally documented by the pathological institutes (online suppl. Fig. 3). Most of the tumours were moderately differentiated (G2 in 42.9\%); the trend history is shown in online supplementary Figure 4; a comparison of register data in online supplementary Table 1. In just under three-quarters of all cases (72.4\%), the regional lymph nodes were not clinically affected (online suppl. Fig. 5). About one-third of the tumours (35.3\%) were categorized in the UICC stage I and further $28.2 \%$ in stage II (Table 1). In $3.0 \%$ of the cases, primary distant metastases were documented. If distant metastases were found, $66 \%$ appeared in the lungs $(n=16$, online suppl. Fig. 2). The mean age of the patients was 67.9 years $(\mathrm{SD}=12.5)$; the age distribution is illustrated in online supplementary Figure 1. Age-standardized rates (ESR) of new cases per 100,000 inhabitants increased from 0.86 to 


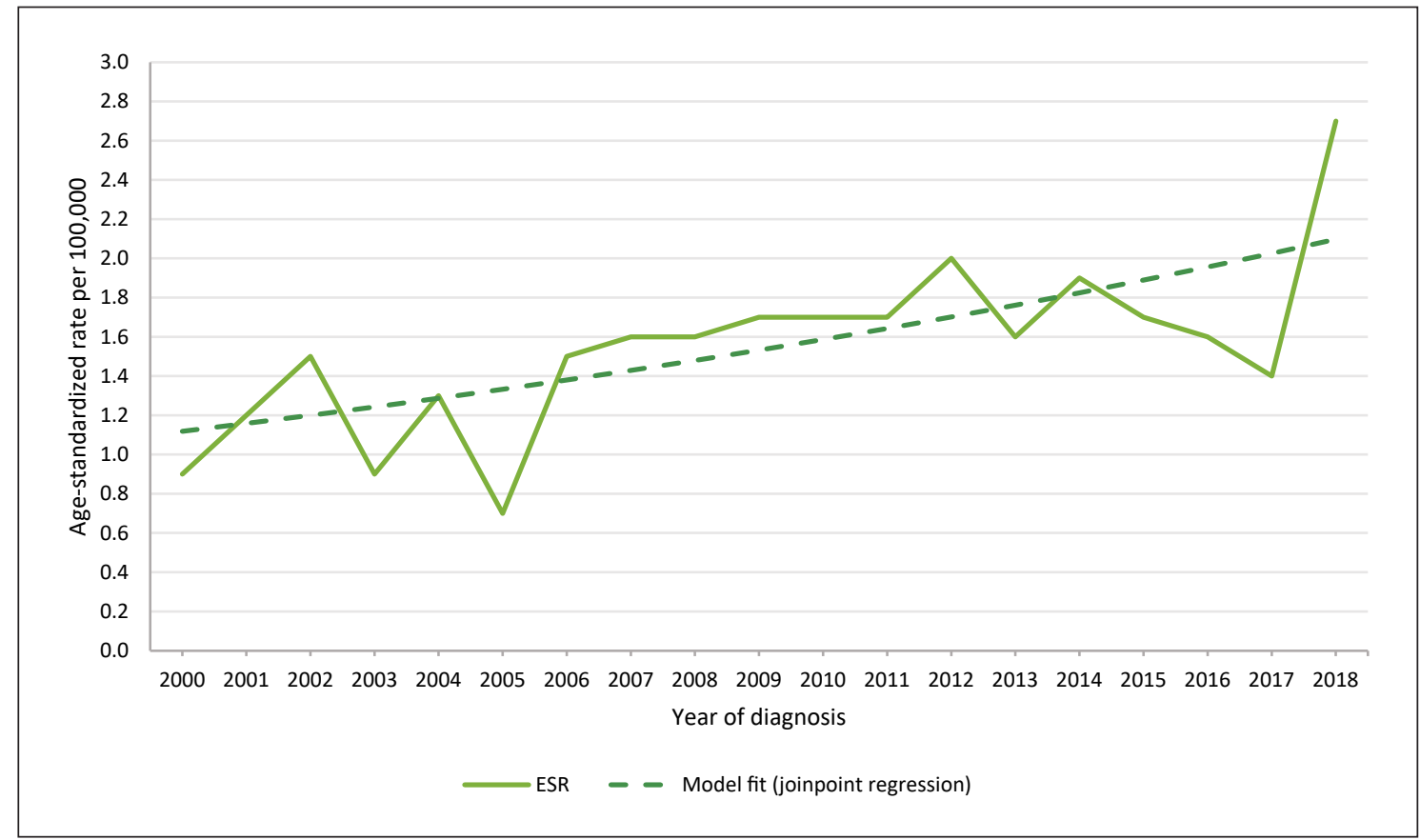

Fig. 1. Standardized incidence rates of penile tumours in Saxony 2000-2018. ESR, European standardized rate.

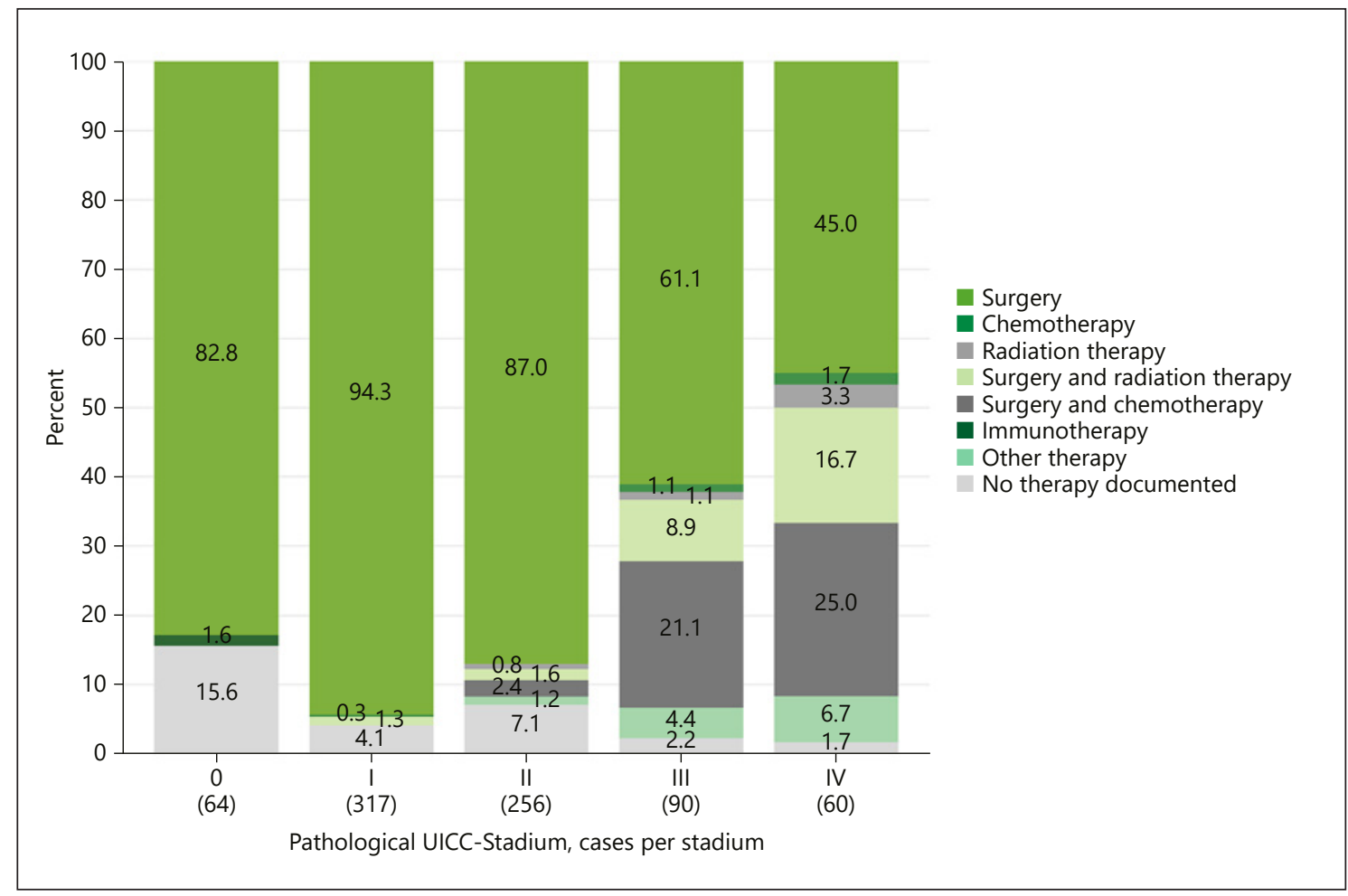

Fig. 2. Documented primary tumour treatment by UICC stage 2000-2018. UICC, Union for International Cancer Control. 
Table 3. Strategy of surgery based on pT tumour stages - in relation to the hospital case volume and to the years of diagnosis, $n(\%)$

\begin{tabular}{|c|c|c|c|c|}
\hline & \multicolumn{2}{|l|}{ pTis, pTa, and pT1 } & \multicolumn{2}{|l|}{ pT2 pT4 } \\
\hline & case volume $<4$ & case volume $\geq 4$ & case volume $<4$ & case volume $\geq 4$ \\
\hline Organ-preserving surgery & $74(42.8)$ & $65(39.4)$ & $6(5.4)$ & $6(4.5)$ \\
\hline Partial/total amputation & $99(57.2)$ & $100(60.6)$ & $105(94.6)$ & $126(95.5)$ \\
\hline \multirow[t]{3}{*}{ Total cases } & 173 & 165 & 111 & 132 \\
\hline & \multicolumn{2}{|l|}{ pTis, pTa, pT1 } & \multicolumn{2}{|l|}{ pT2 - pT4 } \\
\hline & 2000-2009 & 2010-2018 & 2000-2009 & 2010-2018 \\
\hline Organ-preserving surgery & $72(39.8)$ & $131(48.3)$ & $7(5.5)$ & $10(5.6)$ \\
\hline Partial/total amputation & $7(60.2)$ & $140(51.7)$ & $121(94.5)$ & $167(94.4)$ \\
\hline Total cases & 181 & 271 & 128 & 177 \\
\hline
\end{tabular}

Table 4. Lymph node dissection based on pT tumour stages

\begin{tabular}{|c|c|c|c|c|}
\hline & \multicolumn{2}{|l|}{$<\mathrm{pT} 1 \mathrm{G} 2$} & \multicolumn{2}{|l|}{$\geq \mathrm{pT} 1 \mathrm{G} 2$} \\
\hline & case volume $<4$ & case volume $\geq 4$ & case volume $<4$ & case volume $\geq 4$ \\
\hline \multicolumn{5}{|c|}{ (a) According to hospital case volume, $n$ (\%) } \\
\hline Lymph node dissection & $7(8.3)$ & $5(7.1)$ & $55(39.9)$ & $59(39.6)$ \\
\hline No lymph node dissection & $77(91.7)$ & $65(92.9)$ & $83(60.1)$ & $90(60.4)$ \\
\hline \multirow[t]{3}{*}{ Total cases } & 84 & 70 & 138 & 149 \\
\hline & \multicolumn{2}{|l|}{$<\mathrm{pT} 1 \mathrm{G} 2$} & \multicolumn{2}{|l|}{$\geq \mathrm{pT} 1 \mathrm{G} 2$} \\
\hline & 2000-2009 & 2010-2018 & 2000-2009 & 2010-2018 \\
\hline \multicolumn{5}{|c|}{ (b) According to the year of diagnosis, $n$ (\%) } \\
\hline Lymph node dissection & $4(4.6)$ & $14(9.6)$ & $59(34.5)$ & $84(31.2)$ \\
\hline No lymph node dissection & $83(95.4)$ & $132(90.4)$ & $112(65.5)$ & $185(68.8)$ \\
\hline Total cases & 87 & 146 & 171 & 269 \\
\hline
\end{tabular}

2.67 in the period from 2000 to 2018 . This results in an annual percentage change of 3.55 (95\% CI: 1.62-5.53) over this period of 18 years. The increase is statistically significant $(p=0.0012)$. In addition, there is no evidence of a change (joinpoint) in this time trend (Fig. 1).

\section{Surgery}

The clinical tumour stage determines the choice of therapy comprehensibly. Surgery was the most frequent form of therapy in all clinical stages. Patients in stage I (94.3\%) and stage II ( $87.0 \%)$, respectively, were solely treated by surgery. In the more advanced stages III and IV, an extended indication using adjuvant chemotherapy and/or radiation (ERBT) was applied in addition to surgery (Fig. 2).
In this context, we also investigated the aspect, how many of the surgically treated patients in groups A (pTIS, pTa, and pT1) and B (pT2/Corp. spong.) formed based on tumour stages received organ-preserving/sparing surgery. We analysed the relationship of the $2 \mathrm{pT}$ - groups to the case volume of the clinics and subsequently over 2 longer periods. The results are summarized in Table 3. Accordingly, the proportion of organ-preserving surgery in the group of pTis, pTa, and pT1 tumours increased in $2000-2009$ from $39.8 \%$ to $48.3 \%$ in $2010-2018$; at the same time, the proportion of partial/total resections for this group decreased from $60.2 \%$ to $51.7 \%$ with a trend coefficient of $0.44 \% /$ year $(p=0.0045)$. For the group of pT2 - pT4 - tumours, we were able to find a clear con- 
Fig. 3. Five-year relative survival by all risks, $n=749$.

Table 5. Indication spectrum of systemic chemotherapy in relation to the hospital case volume and to the year of diagnosis in 2 periods, $n(\%)$

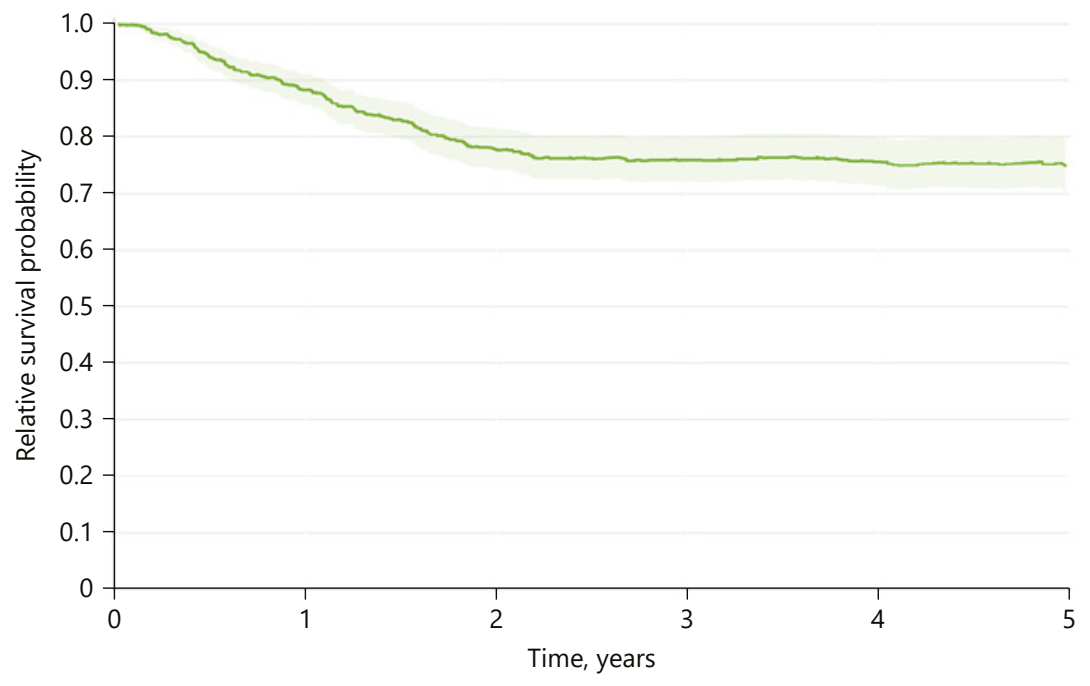

Case volume $<4$ Case volume $\geq 4$

Neoadjuvant and adjuvant chemotherapy according to hospital case volume, $n(\%)$ Neoadjuvant chemotherapy $\quad 15(5.1) \quad 31(10.1)$ $\begin{array}{lll}\text { Adjuvant chemotherapy } & 14(4.7) & 28(9.2)\end{array}$ Total cases

$296 \quad 306$

$2000-2009$ $2010-2018$

Neoadjuvant and adjuvant chemotherapy according to year of diagnosis, $n(\%)$ $\begin{array}{lll}\text { Neoadjuvant chemotherapy } & 31(9.7) & 24(5.2)\end{array}$ Adjuvant chemotherapy $27(8.4) \quad 23(4.9)$ Total cases
466 stancy in the indication for partial/total resection with 94.5-94.4\%. These relations apply to all clinics, regardless of the number of cases/year.

In our data, an established negative surgical margin (R0) was found in only $70 \%$ of the cases. In an undulating course since 2012, the positive surgical margin (Psm) quota shows a continuous rise. In $15.1 \%$ of the histopathological findings, RX status was documented. The recurrences in the follow-up showed $8.7 \%$ as local recurrences, followed by a secondary lymphogenous metastasis in $7.3 \%$ and distant metastases in $2.8 \%$ of the cases (Table 2 ).

\section{Inguinal Lymph Node Dissection}

In $32.0 \%$ of all documented cases, a stage-related lymphadenectomy was carried out. In the subgroup of patients in the tumour stage $>/=$ pT1G 2 was in only $n 287$
(31.9\%), an inguinal lymph node dissection (ILND) is performed. The allocation according to the case volume of the clinics $>/=4$ /year. versus $<4$ /year yielded no significant differences with $39.6 \%$ versus $39.9 \%$. Also, in comparison of 2 evaluation periods of 2000-2009 and 2010-2018, the proportion of ILND performed in stage $>/=$ pT1G2 remained stable at $34.5 \%$ versus $31.2 \%$ (Table 4 ).

\section{Antineoplastic Systemic Chemotherapy}

The analysis of all 898 documented new cases revealed a proportion of $12.1 \%$ lymphogenic metastatic patients; in a further $3 \%$, distant metastases were registered (Table 1). The indication for a neoadjuvant or adjuvant therapy is combined in Table 5. Thereafter, the clinics treated with (relatively) higher case numbers in both indication fields much more offensively (overall $19.3 \%$ vs. $9.8 \%$ ). On 
Fig. 4. Five-year relative survival by UICC stage, $n=749$. UICC, Union for International Cancer Control.

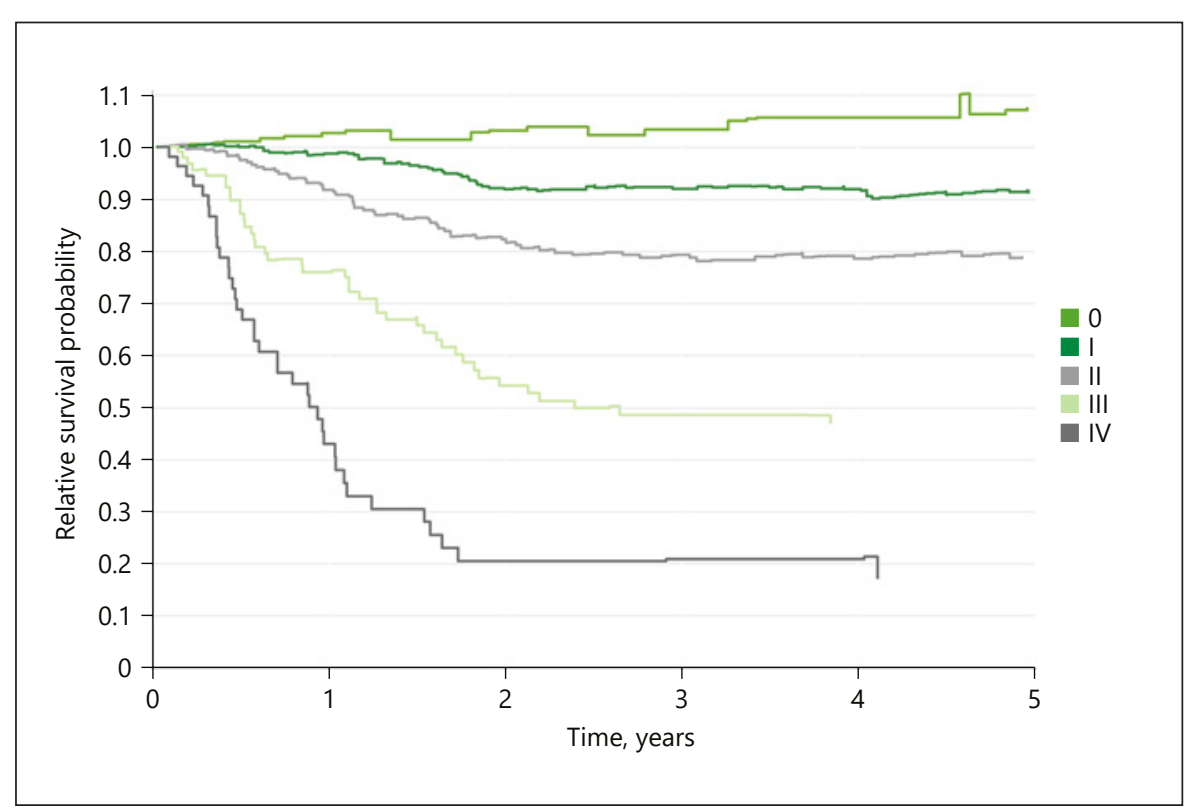

Table 6. Relative survival rates after stratification by pUICC stage and cases of surgery/clinic

\begin{tabular}{|c|c|c|c|c|}
\hline & \multicolumn{2}{|l|}{ pUICC stage 0-II } & \multicolumn{2}{|l|}{ pUICC stage III/IV } \\
\hline & $\begin{array}{l}\text { low volume } \\
\text { (<4 OP/year) }\end{array}$ & $\begin{array}{l}\text { high volume } \\
\text { ( } \geq 4 \text { OP/year) }\end{array}$ & $\begin{array}{l}\text { low volume } \\
\text { (<4 OP/year) }\end{array}$ & $\begin{array}{l}\text { high volume } \\
\text { ( } \geq 4 \text { OP/year) }\end{array}$ \\
\hline 1 year & $98.0(94.5-101.5)$ & $94.8(90.7-99.1)$ & $55.5(42.3-73.0)$ & $75.4(64.7-87.8)$ \\
\hline 2 years & $90.3(84.5-96.5)$ & 89.4 (83.6-95.6) & $39.6(27.0-58.1)$ & $45.6(33.4-62.3)$ \\
\hline 3 years & 91.9 (85.7-98.6) & 87.3 (80.6-94.5) & $35.1(22.9-53.9)$ & $43.6(31.1-60.9)$ \\
\hline 4 years & $92.6(85.7-100.1)$ & 87.3 (79.9-95.3) & $30.1(18.4-49.2)$ & $43.6(31.1-60.9)$ \\
\hline 5 years & $90.3(82.3-99.2)$ & 86.7 (78.6-95.7) & $30.1(17.8-49.2)$ & $41.8(29.1-60.1)$ \\
\hline Total cases & 185 & 195 & 46 & 60 \\
\hline
\end{tabular}

UICC, Union for International Cancer Control.

the other hand, in comparison of the 2 observation periods, an equally clear decline in the applications of systemic chemotherapy seems to be evident (overall 18.1\% vs. $10.1 \%)$.

\section{Survival}

In our analysis including 749 cases, the survival rates for relative overall survival over all clinical stages and risks were $88.3 \%$ (95\% CI 85.7-91.1) after 1 year, 77.8\% (95\% CI 74.3-81.5) after 2 years, and 74.7\% (95\% CI 70.379.4) after 5 years (Fig. 3). The actual dynamics becomes clearer when looking at the UICC stages separately. Relative survival refers to the mortality of the normal population of the region, which is the same age and sex, in each calendar year of survival. Values, for example, $>100 \%$ in stage 0 UICC mean that the study patients are privileged compared to the normal population in terms of their mortality, which is exposed to all causes of death. The explanation for this is given by the procedure of closedmeshed qualified aftercare (Fig. 4). The data further prove that relative overall survival is decisively determined through the stages III and IV in the first 2 to 3 years; after that, the probability of survival hardly changes anymore.

According to our data, 4 hospitals in Saxony operated 314 cases, that is, $\geq 4$ operations per year in the control period. Another 25 departments additionally reported a total of 308 cases, that is, $<4$ operations per year in the same period (online suppl. Fig. 7). With a view to the relative unequal distribution of the data with a presumed discrimination value of 4 operations/year, the interpreta- 
tion of the results is difficult. An advantage could result for stages pUICC III/IV in the experienced clinics (Table 6; online suppl. Fig. 7).

\section{Discussion}

The age-standardized rate of new cases showed a continuous and statistically significant positive trend towards 2.67 new cases per 100,000 (ESR). This development cannot be explained by an improved reporting behaviour to the clinical cancer registries. Since documentation has remained at a high level for 20 years now, it seems more likely that the demographic trend in Germany is responsible for increased rates [16].

In 2015, the results of an evaluation of the Swedish $\mathrm{Na}$ tional Penile Cancer Registry for the years 2000-2012 were presented with 1,678 penile carcinomas [3]. Accordingly, the incidence was 2.1 , and the relative 5 -year overall survival was $82 \%$ (95\% CI 78-85\%), compared to our German data with $74.7 \%$ (95\% CI 70.3-79.4). The guideline adherence rate in Sweden was most recently $71 \%$ to the aspect of organ-preserving surgery, and $64 \%$ for invasive lymph node staging - in centres [3].

Mao et al. [13] presented the data of 3,195 patients from the SEER Database of the National Cancer Institute (NCI) Bethesda; these patients had been diagnosed in the years from 2004 to 2015. The authors compared these data with those of their own study of 69 patients at Tenth People's Hospital of Tongji University Shanghai from the years 2013-2017.

We adapted our findings to the grading for a direct comparison with the cited NCI registry. There was no distinguishing data on the G1/G2 status - it was summarized as one histopathological grade. The resulting small proportion of G1/G2 tumours in the Swedish National Penile Cancer Registry (NPECR) compared to the other registry data appears to be explained by the high GX/ missing rate of the Swedish data (online suppl. Table 1).

The differentiation between G1 and G2 is characterized of a high interobserver variability. Specialized expertise is needed to encounter the conceivable loss of prognostically relevant information [17-19]. Our data clearly show this for the institutes involved. In this respect, the relation of the G1-G2 findings varies just as markedly as does the G3-G4 status on the other hand. We have also found an increase in GX evaluations since 2010. The prognostically significant differentiation in the $\mathrm{T} 1 \mathrm{a} / \mathrm{T} 1 \mathrm{~b}$ category was widely introduced on a regular basis in pathological institutes in 2010. This results in the apparent proportional changes for the pT1 also during the documentation (online suppl. Fig. 7). In $8.3 \%$ of the cases however the "pT1" continues to be conventionally documented by the pathological institutes in Saxony. These facts show an even more inadequate acceptance of guidelines.

With the guideline recommendations of the European Association of Urology (EAU), the penile resection margin to the tumour was changed by recommendation to 1 $\mathrm{mm}$, strictly dependent on the grading [20]. The current S3 guideline of the German Society for Urology (DGU) from 2020 recommends a distance of "at least one to a few millimetres." Minhas et al. [21] showed positive margins were also however found in $6 \%$ of the cases. After a 26-month follow-up, the authors found local recurrence in $4 \%$. In our analysis, we found positive surgical margins in $6.5 \%(\mathrm{R} 1)$ and $7.6 \%$ (R2) quota. Our data show remarkable concordance in this regard. We are sure however that a valid grading in rapid cutting is not practicable due to the limited quality of the freezing cuts and the tumour heterogeneity. Thus, a "grading-based" resection distance is only an interesting discussion approach.

In this context, the documented rate of local recurrences is of clinical significance in the follow-up. In our analysis of 898 patients across all clinical stages, we found a local recurrence in 78 patients $(8.7 \%)$. This quota emphatically confirms literature references with postoperative recurrence rates between 2.7 and 17.6\% [10]. Apparently, now the aspects of quality of life and local performance are given priority over recurrence safety since local recurrences were less complicated to treat, and survival was not impacted [6].

Primary operative therapy of the penile SCC has undoubtedly further the highest priority. In our study, primary surgical monotherapy was also indicated on average in $78.3 \%$ of all cases (Fig. 2). With a view to functionality and the psychosocial outcome, the guidelines strongly recommend a stage-based, organ-preserving strategy $[6,20]$.

Our analyses however attest to a continued high percentage of partial or total penile resection-techniques in Stage pT2-pT4 with $94.4 \%$. The proportion of partial resections in the early clinical stages (pTis, pTa, and pT1) has been reduced from $60.2 \%$ to $51.7 \%$ from 2000 to 2018 . We verify so positive trend shifts through the implementation of the guideline recommendations for the period from 2000 to 2018. By contrast in 2019, Bada et al. [22] described an (partial) amputation rate of just only $39 \%$ in a multicentric, retrospective European study on EAU guideline adherence in 176 patients.

Even though the SCCP is initially deemed radiosensitive, the data situation for the effectiveness of radiation therapy is still not sufficiently good with respect to the 
different morphological variants of SCCP. Advantages of initial organ preservation of $\mathrm{T} 1$ and $\mathrm{T} 2$ tumours through brachytherapy with good local control, like surgery, must be weighed up against local complications. EBRT for T4 tumours is an alternative to surgery with neoadjuvant chemotherapy. Radiation of $\mathrm{N}+$ lymph node disease is not yet evidence-based $[6,20]$. The $\mathrm{S} 3$ guidelines of the DGU [6] consensually recommend explicit clarification about lower local control following EBRT as opposed to surgery. Juanita Crook published the current indications and therapy results of radiation therapy in early stages of a local primary tumour and in the metastatic stage of the disease in a convincing review in 2016 [9].

In our study, radiation therapy (EBRT) was indicated defensively in only $4.2 \%$ of all new cases in the observation period. Adjuvant to surgery $3.0 \%$ of all cases were treated with EBRT. In the palliative, symptomatic indication we found a combination with EBRT in $8.9 \%$ (stage UICC III) and 16.7\% (stage UICC IV) and chemotherapy in $0.3 \%$ of all cases.

The antineoplastic systemic chemotherapy, mostly following the Pizzocaro protocol [23], likewise appears to play only a subordinated role of our study with $6.0 \%$ of all new cases. In a subanalysis following the UICC stages, the distribution of the therapy forms corresponding to the clinical situation becomes more transparent as a result. The need of chemotherapy in combination with surgery was seen in $21.0 \%$ of stage III disease and only to $25.0 \%$ in stage IV disease of our patients. In our data, we found a more aggressive willingness to use cytotoxic chemotherapy in clinics with larger case volumes/year and consecutively, an increase in clinical experience. During the recording period of 18 years, the decision for chemotherapy has also surprisingly decreased; whether the still unsatisfactory remission rates are the cause of this could not be evaluated from the statistical material alone.

In 2018, A Baumgarten et al. [24] published the results of an international retrospective multicentric cohort study on organ-preserving surgery of the SCCP. They found pT2 stage in $33.2 \%$ of their cases and confirmed a relative 5 -year survival rate in $75.9 \%$ of the cases. In the Swedish NPECR, the percentage of pT2 tumours was 19\% [3]; in our study, we found pT2 tumours proportionately in $23.5 \%$ of the cases and in $28.2 \%$ in stage II. We determined the relative survival for the 5-year survival of this clinical study to be $78.9 \%$ (95\% CI 70.9-87.9\%).

Our investigations about the dependence of relative survival on the annual number of cases did not yield any significant advantage due to the typically low frequency of new cases/year. With a view to the relative unequal dis- tribution of the data with a presumed discrimination value of 4 operations/year/clinic, the interpretation of the results is difficult (Table 6; online suppl. Fig. 7).

\section{Conclusions}

Based on the critical evaluation of some of the relevant variables/quality indicators in the registry (case numbers, grading evaluation, status of resection margins, and partial resection quota) in our study, we recommend establishing SCCP reference clinics. In these conceptual consequences, we are in complete agreement with Williams et al. [25] concerning an internationally developed systematic review for coordinated centralized care in the field of uro-oncology.

The present structures for the compulsory cross-progression and cross-sectoral documentation of processes at all clinical care levels have largely established themselves in practice including the quality evaluation and implementation of guidelines and the specification within the scope of certifications [26]. The objective of our study was to show incidences and therapy trends of SCCP in Saxony/Germany to illustrate clinical characteristics in a big population-based clinical cancer registry.

\section{Statement of Ethics}

The article is exempt from Ethical Committee approval because of methodically and strictly descriptive-retrospective data evaluation.

\section{Conflict of Interest Statement}

The authors declare that they have no conflicts of interest.

\section{Funding Sources}

The work of the clinical cancer registries in Germany is financed by health insurance. No external funds were provided for the current analysis and publication. This work is co-financed with tax revenues on the basis of the budget enacted by the State Parliament of Saxony.

\section{Author Contributions}

D. Piontek and O. Schoffer had full access to all the data in this study and take responsibility for the integrity of the data and the accuracy of the data analysis. Study concept and design were conceived by W.-D.U. Boehm, D. Piontek, and S.J. Klug. Analysis and 
interpretation of data were performed by W.-D.U. Boehm, D. Piontek, M.P. Wirth, and O. Schoffer. Drafting of the manuscript was performed by W.-D.U. Boehm, D. Piontek, and S.J. Klug. Critical revision of the manuscript for important intellectual content was performed by M.P. Wirth, S.J. Klug, and A. Borkowetz. Statistical analysis was performed by D. Piontek. Administrative, technical, or material support was provided by S. Latarius. Supervision was performed by W.-D.U. Boehm, M.P. Wirth, and S.J. Klug. The authors are grateful for the friendly assistance of the Clinical Cancer Registries in Chemnitz (B. Schubotz), Dresden (C. Werner), Leipzig (S. Klagges), and Zwickau (J. Wulff).

\section{Data Availability Statement}

All data generated or analysed during this study are included in this article and its online supplementary material. Further enquiries can be directed to the corresponding author.

\section{References}

1 FRANCIM network; Daubisse-Marliac L, Colonna M, Trétarre B, Defossez G, Molinié F, Jéhannin-Ligier K, et al. Long-term trends in incidence and survival of penile cancer in France. Cancer Epidemiol. 2017;50:125-31.

2 Hansen BT, Oruma M, Lie AK, Brennhovd B, Nygard M. Trends in incidence, mortality, and survival of penile squamous cell carcinoma in Norway 1956-2015. Int J Cancer. 2018; 142(8):1586-93.

3 Kirrander P, Sherif A, Friedrich B, Lambe M, Hakansson U, on behalf of the Steering Committee of the Swedish National Penile Cancer Register. Swedish National Penile Cancer Register: incidence, tumour characteristics, management, and survival. BJU Int. 2014; 117(2):287-92.

4 Barnholtz-Sloan JS, Maldonado JL, Pow-Sang J, Giuliano AR, Guiliano AR. Incidence trends in primary malignant penile cancer. Urol Oncol. 2007;25:361-7.

5 Colberg C, van der Horst C, Jünemann KP, Naumann CM. Epidemiologie des peniskarzinoms. Urologe. 2018;57(4):408-12.

6 Schoffer O, Neumann A, Stabenow R, Schülein S, Böhm WD, Gonsor A, et al. Penile cancer - Incidence, mortality and survival in Saxony, Germany. Urol Oncol Semin original Invest. 2019;37(4):295.e1-8.

7 Leitlinienprogramm Onkologie (Deutsche Krebsgesellschaft, Deutsche Krebshilfe, AWMF): S3-Leitlinie Diagnostik, Therapie und Nachsorge des Peniskarzinoms, Langversion 1.0 - 2020. AWMF-Registriernummer 043-04OL. https://www.leitlinienprogrammonkologie.de/leitlinien/peniskarzinom.

8 Erbersdobler A. Pathologie und histopathologische begutachtung des peniskarzinoms. Urologe. 2018;57(4):391-7.

9 Crook J. Contemporary role of radiotherapy in the management of primary penile tumors and metastatic disease. Urol Clin North Am. 2016;43:435-48.
10 Protzel C, Hakenberg OW. Lokale therapie beim peniskarzinom. Urologe. 2018;57(4): 423-7.

11 Winters BR, Kearns JT, Holt SK, Mossanen $\mathrm{M}$, Lin DW, Wright JL. Is there a benefit to adjuvant radiation in stage III penile cancer after lymph node dissection? Findings from the national cancer database. Urol Oncol. 2018;36(3):92-e16.

12 Aktualisierter einheitlicher onkologischer Basisdatensatz der Arbeitsgemeinschaft Deutscher Tumorzentren e.v. (ADT) und der Gesellschaft der epidemiologischen Krebsregister in Deutschland e.v. (GEKID) in der Fassung der Bekanntmachung vom 27. März 2014 (Banz AT 28.04.2014 BZ).

13 Mao W, Zhang Z, Huang X, Fan J, Geng J. Marital status and survival in patients with penile cancer. J Cancer. 2019;10(12):2661-9.

14 Wittekind, C. (Hrsg.) (2010 und 2017, 7. und 8. Auflage). TNM-Klassifikation maligner Tumoren, Korrigierter Nachdruck 2020. Weinheim: Wiley-VCH Verlag $\mathrm{GmbH}$ \& CoKGaA.

15 Deutsches Institut für Medizinische Dokumentation und Information (DIMDI) im Auftrag des Bundesministeriums für Gesundheit (BMG) unter Beteiligung der Arbeitsgruppe OPS des Kuratoriums für Fragen der Klassifikation im Gesundheitswesen (KKG) (Hrsg.) (2018). Operationen- und Prozeduren Schlüssel. Internationale Klassifikation der Prozeduren in der Medizin (OPS). Köln: Deutsches Institut für Medizinische Dokumentation und Information (DIMDI).

16 Tillack A, Werner C, Buchali A, Klug SJ. Flächendeckende bevölkerungsbezogene klinische krebsregister: darstellung der versorgungstransparenz in Brandenburg und Sachsen. Onkologe. 2013;19:1065-73.

17 Gunia S, Burger M, Hakenberg OW, May D, Koch S, Jain A, et al. Inherent grading characteristics of individual pathologists contribute to clinically and prognostically relevant interobserver discordance concerning Broders' grading of penile squamous cell carcinomas. Urol Int. 2013;90:207-13.
18 Hakenberg OW, Dräger DL, Erbersdobler A, Naumann CM, Jünemann KP, Protzel C. The diagnosis and treatment of penile cancer. Dtsch Arztebl Int. 2018;115:646-52.

19 Kakies C, Lopez-Beltran A, Comperat E, Erbersdobler A, Grobholz R, Hakenberg OW, et al. Reproducibility of histopathologic tumor grading in penile cancer-results of a European project. Virchows Arch. 2014;464(4):453-61.

20 Hakenberg OW (Chair), Compérat E, Minhas S, Necchi A, Protzel C, Watkin N. Guidelines on Penile Cancer. European Association of Urology; 2018.

21 Minhas S, Kayes O, Hegarty P, Kumar P, Freeman A, Ralph D. What surgical resection margins are required to achieve oncological control in men with primary penile cancer? BJU Int. 2005;96(7):1040-3.

22 Bada M, Beradinelli F, Nyirady P, Varga J, Ditonno P, Battaglio M, et al. Adherence of the EAU guidelines on penile cancer treatment. European multicentre, retrospective study. J cancer Res Clin Oncol. 2009;145:921-6.

23 Pizzocaro G, Nicolai N, Milani A. Taxanes in combination with cisplatin and fluorouracil for advanced penile cancer: preliminary results. Eur Urol. 2009;55:546-51. .

24 Baumgarten A, Chipollini J, Yan S, Ottenhof SR, Tang DH, Draeger D, et al. Penile sparing surgery for penile cancer: A multicentre international retrospective cohort. J Urol. 2018; 199:1233-7.

25 Williams SB, Ray-Zack MD, Hudgins HK, Oldenburg J, Trinh QD, Nguyen PL, et al. Impact of centralizing care for genitourinary malignancies to high-volume providers: a systematic review. Eur Urol Oncol. 2019;2:26573.

26 Klinkhammer-Schalke M, Gerken M, Barlag $\mathrm{H}$, Tillack A. [Quality management in oncology supported by clinical cancer registries]. Z Evid Fortbild Qual Gesundhwes. 2015;109(6): 452-8. 